\title{
COLLATERAL EFFECTS OF LIBERALISATION: METERING, LOSSES, LOAD PROFILES AND COST SETTLEMENT IN SPAIN'S ELECTRICITY SYSTEM
}

\author{
Joan Batalla-Bejerano, Maria Teresa Costa-Campi, Elisa Trujillo-Baute
}

\begin{abstract}
European energy markets have undergone a major transformation as they have advanced towards market liberalisation and it is vital that the details of these developments be carefully examined. The success of liberalisation is based on smart regulation, which has been capable of providing solutions to unforeseen events in the process. Our paper seeks to contribute to existing understanding of the unexpected and collateral effects of the liberalisation process in the power system by examining a natural experiment that occurred in Spain in 2009. In that year, the electricity supply by distribution system operators disappeared. This change in retail market competition, as we demonstrate in this paper, has had an unexpected effect in terms of the system's balancing requirements. We undertake a rigorous assessment of the economic consequences of this policy change for the whole system, in terms of its impact on final electricity prices.
\end{abstract}

JEL codes: D47, L51, Q41, Q42, Q47.

Keywords: electricity market design, balancing services, electricity market balance; liberalisation; natural experiment.

Joan Batalla-Bejerano

Rovira i Virgili University

Chair of Energy Sustainability

Av. Diagonal, 690

08034 Barcelona (Spain)

E-mail: jbatallab@gmail.com

Maria Teresa Costa-Campi
University of Barcelona
Barcelona Institute of
Economics (IEB)
Chair of Energy Sustainability
Av. Diagonal, 690
08034 Barcelona (Spain)
E-mail: mtcosta@ub.edu

Elisa Trujillo-Baute

University of Warwick

Barcelona Institute of

Economics (IEB)

Chair of Energy Sustainability

Coventry CV4 7AL (United

Kingdom)

E-mail: elisatrujillo@ub.edu 


\section{INTRODUCTION}

In the 1990s, when most national electricity and natural gas markets were still monopolies, the European Union and its Member States opted for the gradual opening up of these markets to competition. Significant progress has since been made in this direction in the case of the electricity market thanks to the gradual introduction of competition via a number of legislative packages. Underlying these proposals is the strong conviction that liberalisation increases the efficiency of the energy sector and the competitiveness of the European economy as a whole.

Spain has been no exception in this liberalisation process. In line with the broader trend, the Spanish government established as a priority the opening up of the electricity sector to competition. The Electric Power Act 54/1997 represented the first step in this liberalisation process, with the establishment of a general framework for the electricity sector aimed at guaranteeing competition and competitiveness. Under this new framework, the government defined a transition period towards full liberalisation and while the introduction of tariffs of last resort in the residential electricity market did not increase liberalisation per se (Federico, 2011), it did represent a starting point in the drive to the deregulation of the retail market.

An evaluation of the liberalisation process conducted to date across Europe shows that not all the expected changes, especially those concerning lower electricity prices and effective retail market competition, have yet to be achieved. However, it is not the aim of this paper to analyse the results of the liberalisation process; rather, our objective is to examine some collateral or unexpected effects of the liberalisation process in the energy sector by examining a natural experiment conducted in Spain in 2009. The Second Electricity Directive ${ }^{1}$ and its transposition to national regulation included a number of measures directly concerning distribution system operators (DSOs). Thus, the regulatory framework required the separation of distribution activities from other segments of the electricity value chain (i.e., generation, transmission and supply activities). In the case of Spain, prior to June 2009, distribution companies had also been responsible for supplying consumers under a regulated tariff. However, in July 2009, this regulated supply disappeared and was substituted by a last resort supply system, managed by suppliers of last resort. This change in retail market competition, as we shall demonstrate in this paper, has had consequences in terms of the system's balancing requirements.

An increase in the adjustment service costs of tertiary regulation and deviation management have been observed since 1 July 2009, together with an increase in the corresponding adjustment service costs incorporated in the final electricity price paid by consumers. The aim of this study is to provide a better understanding of the impact of liberalisation on the costs of volume adjustment. We exploit this policy event to compare the costs of adjustment in the periods before and after the policy change. Although demand forecast methods have received special attention from the academia (Cancelo et al., 2008; Ramanathan et al., 1997; Soares and Medeiros, 2008; Taylor, 2006;), when explaining the cost of balancing services, demand

\footnotetext{
${ }^{1}$ Directive 2003/54/EC of the European Parliament and of the Council of 26 June 2003 concerning common rules for the internal market in electricity and repealing Directive 96/92/EC.
} 
deviations effects have not been as deeply studied as the effects that stem from intermittent renewable generation (Ela et al., 2014; Frunt, 2011; Glachant and Finon, 2010; Haas et al., 2013; Hirth and Ziegenhagen, 2015; Hirth et al., 2015; Vandezande et al., 2010).

Within the overall liberalisation process, during which European energy markets have undergone a major transformation, the issue analysed in this paper - energy market balance could be considered a minor question. However, the success of any transformation process lies in applying smart regulations that can provide solutions to unexpected aspects of the process so as to exploit its potential benefits for society. In this new liberalised paradigm, the System Operator (SO) has to be more concerned with real-time system operations and the ability to manage supply and demand constantly given that additional demand deviations induced by the energy market balance can potentially result in new operational reliability issues that need to be analysed.

In this context, drawing on data for the Spanish power market for the period just before and after the regulatory change became effective, this study aims to address the question of the collateral consequences of the liberalisation process in terms of system reliability. The paper seeks to determine whether this policy change means that additional system flexibility is required thus affecting final electricity prices insofar as increasing energy market balance is addressed through ancillary services. Although the liberalisation process undertaken in Spain goes beyond the disappearance of the regulated supply and its impact on power system balancing costs, it is crucial to assess its economic consequences, especially if the last intention of the regulatory change is to benefit all electricity consumers.

The remainder of this paper is structured as follows. Section 2 provides an overview of the policy change under revision and its economic implications. The data used, empirical strategy and model specification are presented in Section 3. Estimation results are presented and discussed in Section 4. The paper ends with a final section summarising research conclusions and presenting the policy and regulatory recommendations.

\section{THE POLICY}

\subsection{Policy design}

2009 was a key year for Spain's electricity sector and, in particular, for its retail markets. On 1 July 2009, end-user regulated electricity prices disappeared along with the DSOs' role as suppliers. Prior to that date, consumers had been able to choose between being supplied by distribution companies - through end-user regulated prices - or by retailers under free market conditions. Distribution companies would no longer be able to supply electricity to their customers.

However, these reforms, which were designed to foster competition in the retail market and to promote progress towards the creation of an efficient Internal Energy Market in the European Union, had collateral and negative consequences for balancing markets in relation to electricity 
system losses and the estimation process of the electricity consumption for those customers without hourly metering. As the energy metered at distribution network entry points (transmission nodes and embedded generation) is not the same as that metered at distribution network exit points owing to the existence of losses, energy demand at the power station busbars $^{2}$ is estimated using a regulated standard coefficient of losses. It should be stressed that the energy estimated according to this procedure does not have to coincide with the amount of energy eventually dispatched, arising hourly energy imbalances (see Figure 1). As a result, the energy dispatched to meet the customers' energy requirements is not necessarily the same as that initially expected by the suppliers, appearing a positive or negative energy difference, for which a balancing process is required.

Figure 1: Hourly energy imbalances (MWh)

explained by differences between real and estimated electricity losses

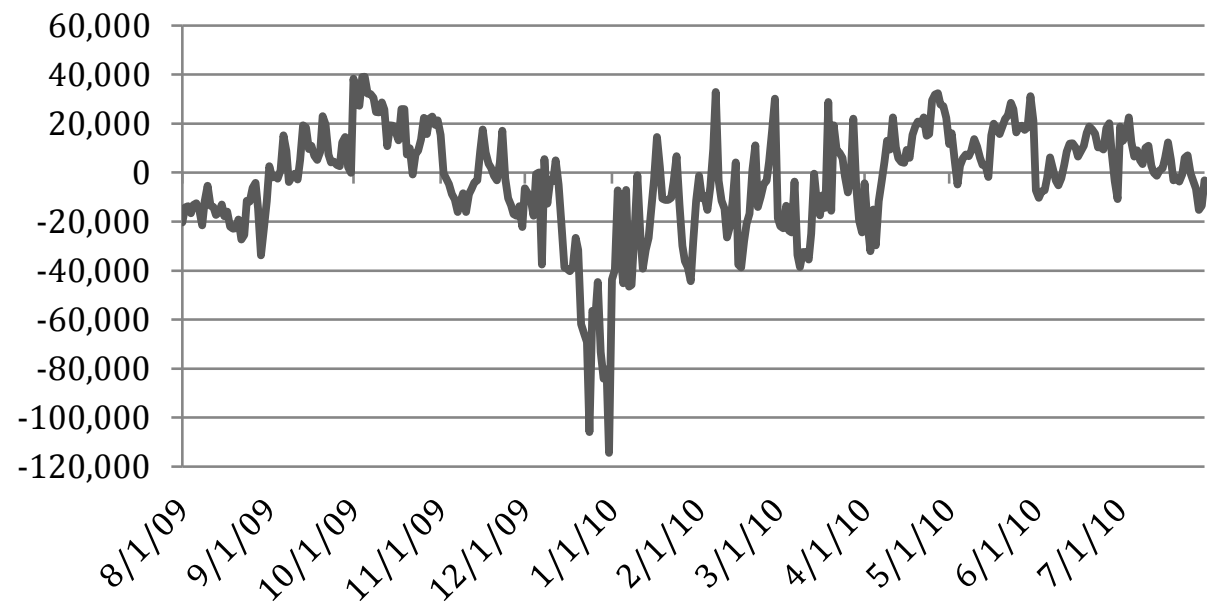

Source: Own elaboration based on data from Spanish National Regulatory Authority (CNMC)

The main difference since July 2009 is the way in which this new energy imbalance is addressed $^{3}$. In the pre-liberalisation system, the energy imbalance was resolved by the DSOs permanently matching electricity demand forecasts with the energy actually dispatched. Under liberalisation, this system is no longer valid. From a regulatory perspective, the electricity imbalances resulting from the difference between the average transport and distribution losses and the standard losses used in balancing the system as a whole are considered additional system deviations. This difference, defined as the energy market balance (EMB), requires additional adjustment services to ensure that energy generation and demand are in permanent equilibrium. Addressing the energy market balance is achieved through ancillary and energy balancing services based, in most instances, on market procedures such as the secondary and

\footnotetext{
${ }^{2}$ The power plant busbar is that point beyond the generator but prior to the voltage transformation in the plant switchyard; it is the starting point of the electric transmission system.

${ }^{3}$ See Appendix for a detailed explanation of the technical aspects underpinning the energy market balance (EMB).
} 
tertiary reserves and the imbalance management process, so there is a direct relationship between the size of the deviation and the cost to the system when solving it.

The analysis of the relationship between the energy market balance and the final electricity price is the main objective of this paper. When a difference arises between the energy measured at the power station busbars and the energy scheduled in the market, the system has to manage that difference by increasing production through the adjustment markets in real time. As explained next, the energy market balance implies economic consequences for both suppliers and consumers, who have to face increasing balancing costs related to the energy adjustment mechanism required to maintain generation and load in permanent equilibrium.

\subsection{Implications and research hypothesis}

From a system management perspective, several factors on both the demand and supply side might cause active power imbalances in the electricity system (see Table 1). Together with physical imbalances, above and beyond the deviations between the stepwise (discrete) demand and supply schedules and continuous physical variables (scheduled leaps), other variables may result in imbalances. Thus, unplanned contingencies in the conventional or renewable generation capacity or in the interconnection capacity, forecast errors from VRES generation due to its intermittent nature or load forecast errors can all increase the need for balancing power. As the electrical system has to be in permanent equilibrium, balancing power (regulating frequency-control power) is used in rapidly restoring the supply-demand balance in systems when an active power imbalance arises.

Table 1: Variables that cause system imbalances

\begin{tabular}{|c|c|c|}
\hline & Variable & Imbalance source \\
\hline \multirow[t]{3}{*}{ Supply } & Conventional generation & $\begin{array}{l}\text { - Unplanned plant outages } \\
\text { - Schedule leaps }\end{array}$ \\
\hline & VRES generation & $\begin{array}{l}\text { - Forecast errors } \\
\text { - Schedule leaps }\end{array}$ \\
\hline & Interconnectors & $\begin{array}{l}\text { - Unplanned line outages } \\
\text { - Schedule leaps }\end{array}$ \\
\hline Demand & Load & $\begin{array}{l}\text { - Forecast errors } \\
\text { - Deviations from standard losses } \\
\text { - Schedule leaps }\end{array}$ \\
\hline
\end{tabular}

Source: based on Hirth and Ziegenhagen (2015)

As explained above, total losses produced in the transmission and distribution networks may be another source of power imbalance. The methodology employed in the Spanish regulatory framework in relation to such losses involves allocating a percentage of these losses to each customer using loss factors or standard coefficients that take into account their consumption 
characteristics. This procedure means that if actual losses differ from standard or regulated losses, the power system has to face a new source of imbalance.

The existence of demand deviations in power systems is not something new. The aim behind the liberalisation process across Europe implemented during the last decade was to open up the electricity supply to competition. At that moment, and in order to avoid huge and prohibitive costs of putting smart metering into every customer, it was a common approach that some specific electricity consumers - mainly residential - would be settled using load profiles and ex-ante fixed loss coefficients. In this sense, deviations from standard losses have to be considered as an additional source of uncertainty to power system managers together with the inherent forecast errors and schedule leaps.

In this context and even with perfect VRES-E generation forecasting, ceteris paribus the consequences for electricity systems of an increasing difference between the estimated demand and the final load should be a need for additional flexibility. In terms of system operation, this energy gap should stress the need for an appropriate number of reserve power plants with flexible dispatch capable of providing the necessary stability and ancillary services to deal with problems of electricity market balance.

In this paper, we test whether a sub-optimal definition of the standard coefficient of losses means that the system operator has greater losses to solve in real-time in order to balance the markets. At the same time, we examine whether the way in which this policy consequence is being addressed affects the market price signals for the rest of the balancing energy required.

The Spanish electricity market is organized as a sequence of different markets - a day-ahead market, an intraday market, ancillary services - and system operation services beginning with the day-ahead market and culminating in real time ${ }^{4}$. Once the day-ahead market closes, additional short-term tools have to be implemented to enable participants or the system operator to improve the schedules defined during the previous day (Pérez-Arriaga and Batlle, 2012). Under trading enabling them to react when supply or demand situations change with respect to the estimates cleared on the day-ahead market. Finally, ancillary services include the set of products that are separated from the energy production, and which are related to the power system's security and reliability (Lobato et al., 2008). These services, though not including voltage control ancillary services, are designed to ensure the necessary equilibrium between generation and demand and include load-frequency control and balancing ancillary services.

Although a detailed description of the design and characteristics of the different ancillary service (AS) markets - primary control, secondary control, tertiary control and balancing ancillary services - lies beyond the scope of this paper, Figure 2 illustrates the expected effects of the policy under analysis on AS markets. To understand these effects properly, a number of considerations must first be made. In Spain, as in most countries' power systems, several types of balancing power are employed simultaneously to address power and load imbalances. These balancing power types can be distinguished along several dimensions (Hirth and Ziegenhagen,

\footnotetext{
${ }^{4}$ For a more detailed description of the Spanish electricity market see Bueno-Lorenzo et al. (2013).
} 
2015): operating vs. contingency reserves, spinning vs. stand-by reserves, fast vs. low regulation in terms of the activation time, positive or upward regulation vs. negative or downward regulation, etc. Depending on the type of balancing power market, the technical characteristics of the service provided differ. Thus, each has different market designs and different ways of addressing resource adequacy and reserve margin issues. To explain the expected consequences of the policy change in the ancillary services market, in Figure 2 we assume that all the balancing energy required to solve imbalances is cleared in a single competitive balancing market, where suppliers of balancing power only receive compensation for energy (and none for capacity) based on the marginal price.

In the simplified ancillary services market, the market equilibrium price $\left(P_{a s}\right)$ results from the intersection of the demand $(D)$ and supply $(S)$ curves. This price determines the economic cost associated with the provision of the balancing energy required $\left(Q_{a s}\right)$ by the System Operator to stabilize the active power balance on short time scales. The electricity market balance process used to solve biased loss estimations might increase the total amount of balancing power needed thus leading to a change in demand. Graphically, this new balancing requirement $\left(Q_{a s}\right.$ ' - $\left.Q_{a s}\right)$ involves a shift in the demand curve to the right $\left(D^{\prime}\right)$ resulting in a new market price equilibrium $\left(P_{a s}{ }^{\prime}\right)$.

Two direct economic effects can be identified if we examine the policy implications of balancing market. The first (the quantity effect) concerns the increase in the total balancing cost needed to reserve the band of secondary regulation and for the additional spinning reserves for tertiary purposes caused by EMB $\left(\left(Q_{a s}{ }^{\prime}-Q_{a s}\right) \times P_{a s}{ }^{\prime}\right)$. Additionally, an increase in demand will shift prices upward, increasing the overall economic value of balancing relative to the prior equilibrium point. This second impact (price effect) concerns the increase in the total balancing cost explained by a higher equilibrium price than that at which the previous equilibrium quantity is cleared $\left(Q_{a s} x\left(P_{a s}{ }^{\prime}-P_{a s}\right)\right)$. Both effects refer to the total economic cost of balancing power procurement. In this paper, we test if liberalisation (i.e., the policy change) results in a shift of both the price and quantity in balancing markets, increasing the overall cost of the provision of this service relative to the prior equilibrium point.

Figure 2: Expected effects of the policy on ancillary services market

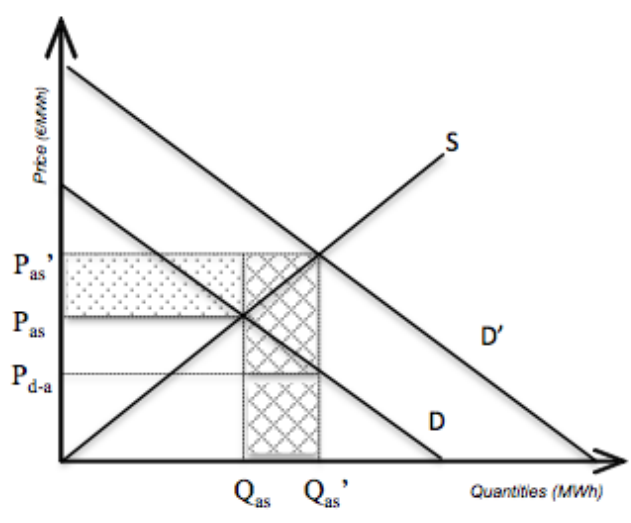


At different market sessions held the day prior to or even on the day of delivery, the final price of electricity is determined as the sum of the different prices and costs associated with each of these markets. The determination of the economic cost associated with each electricity market and the allocation criteria of this cost strongly depend on market design characteristics. Increasing energy market balance is addressed through ancillary and energy balancing services based, in most cases, on market procedures such as secondary and tertiary reserves and imbalance management processes, so there is a direct relationship between the size of the deviation and the cost to the system for solving it. Demand for larger balancing energy might have economic impacts on final electricity prices and the analysis conducted in this paper seeks to obtain empirical findings of this nexus based on Spanish market data.

Power system reliability and resource adequacy are complex elements of market operations where the final cost is influenced by multiple factors. While there is, in principle, a general consensus on the nexus between energy loss deviations from expected and balancing power, no empirical analyses have examined the size of the impact. The absolute economic impact of the policy change in terms of balancing costs is by no means a straightforward question due to the complex nature of wholesale, intraday and ancillary services markets where many variables can impact on final prices and generator revenues (location, raw material costs, generation mix, level of demand, size of the electricity imbalances, etc.). The aim of this paper is to contribute to a better understanding of the economic consequences of the liberalisation by undertaking an evaluation of its impact on final balancing power cost.

From a welfare perspective, the economic consequences for consumers are evident as the energy imbalance is addressed in posterior markets where prices are typically higher. Realtime market clearing prices, also known as balancing energy prices, are generally by their nature much more volatile and higher than day-ahead prices. Therefore, an increase in the volume of balancing energy required to solve deviations between estimated and real loads should have an economic impact on the final hourly electricity price paid by the consumers.

\section{DATA AND EMPIRICAL STRATEGY}

As explained above, the Spanish electricity market comprises different sub-markets: a daily market, an intraday market, ancillary services and system operation services beginning with the day-ahead market and culminating in real time. The system operator, Red Eléctrica de España (REE), manages the primary, secondary and tertiary regulation, in order to guarantee the stability of the system. All the adjustment services are made available via different system operation processes defined by REE. One of the most remarkable features of the Spanish system is that, since the beginning of the liberalisation process, the regulatory framework has promoted the provision of these services through market mechanisms, along with the creation of the market as a platform for energy transactions. Drawing on data for these markets, operating reserve costs have been calculated. Operating reserves, often referred to as ancillary services, include contingency reserves - the ability to respond to a major contingency such as an unscheduled power plant or transmission line outage - and regulation reserves - the ability 
to respond to small and random fluctuations around the expected load (Ela et al., 2014; Hummon et al., 2013; IEA, 2009, 2011a and 2011b).

As pointed out in previous sections, deviations between scheduled energy and real time demand are addressed through ancillary services, most of which are based on market procedures, such as the secondary and tertiary reserves and the imbalance management process. Therefore, there is a direct relationship between the size of the deviation and the cost to the system of solving it. Using hourly market data for Spain, the weighted average cost of the system adjustment services - technical constraints, secondary control, tertiary control, power reserve, deviation management and real-time constraints - is used as the dependent variable in the econometric estimation. To examine the impact of the policy we distinguish between two periods. The first covers the 12-month period prior to policy change, from 1 July 2008 to 30 June 2009. The second covers the 12-month period after the policy became effective, from 1 July 2009 to 30 June 2010. We choose one-year periods to minimise the probability that seasonal patterns might account for the results we find. We looked for information about other related policy changes in both periods that might affect our research, but to the best of our knowledge there were none. Hence, we are confident that the policy change under consideration is the sole policy event in our sample.

The adjustment (or operational) cost, defined as the economic cost of the balancing mechanisms that are required when demand or supply deviations appear, is defined as the price spread between the final electricity price and the price at the end of the last intraday market session. After the intraday market, deviations between scheduled and measured energy are addressed through market procedures, such as secondary reserve, tertiary reserve and the imbalance management process. The costs associated with these balancing markets are captured by this spread, which measures the additional costs for delivering one MWh of electricity on top of the day-ahead and intraday price. When obtaining this spread, capacity payments ${ }^{5}$ are not considered. In other words, the adjustment cost results from the aggregate of the overall system adjustment services managed by the SO - technical and real-time constraints, power reserve, secondary and tertiary control bands and deviation management services -

Based on the foregoing considerations and bearing in mind that the final electricity price is determined as the sum of the different prices and costs associated with each of the markets that integrate the power system, the adjustment service cost (ASC) is obtained as shown in the following equation (with all variables expressed in $€ / \mathrm{MWh}$ ):

$$
A S C_{t}=F P_{t}-D A M P_{t}-I M P_{t}-C P_{t}
$$

where:
$A S C_{t}$ :
Adjustment service cost
$F P_{t}$ :
Electricity final price

\footnotetext{
${ }^{5}$ Capacity payments correspond to the regulated retribution to finance the medium- and long-term power capacity service offered by the generation facilities to the electricity system. Given that they are not directly related to the procurement of flexibility to the system, this cost is not included.
} 


$\begin{array}{ll}D A M P_{t}: & \text { Day-ahead market price } \\ I M P_{t}: & \text { Intraday markets price } \\ C P_{t}: & \text { Capacity payments }\end{array}$

Although several factors - unplanned plant outages in thermal and hydro generation, forecast errors in VRES-E generation, unplanned line outages of international interconnectors and forecast errors of load, among others - could result in active power imbalances in electricity systems, our empirical approach focuses on demand deviations explained by differences between the real losses of the system and those resulting from the application of a standard coefficient of losses and load profiles.

To understand how this explanatory variable is calculated, we first need to provide an overview of how active power imbalances are addressed in Spain's electricity system. As electricity cannot be stored in large quantities, the amount of energy demanded must be generated with great precision in the exact moment that it is required, ensuring a constant balance is maintained between generation and consumption. Using day-ahead market and physical bilateral contracts, purchase and sales bids are made resulting in the scheduled energy program. From the perspective of energy flows (Figure 3), demand and supply are integrated by different components. Following intraday market gate closure, the $\mathrm{SO}$ has to adjust the resulting program to compensate for any modification or deviation in any of these components. Energy deviations that occur after the intraday gate closure constitute real demand adjustments (RDAs), the latter being attributable to several possible factors. Any difference between expected and real demand from liberalised and last resort retailers (without considering technical and commercial losses) or any real losses different from expected standard losses, increase the need for energy used in the RDA process. Given that demand deviations explained by EMB constitute one of the most relevant explanatory variables accounting for RDAs, they have been used as a proxy variable of the effect of the policy under analysis.

Figure 3: Spanish (peninsular) electricity balance

\begin{tabular}{|c|c|c|c|c|}
\hline \multirow{10}{*}{ 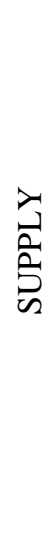 } & \multirow{9}{*}{$\begin{array}{ll} & \text { Total net generation } \\
- & \text { Conventional } \\
- & \text { Pumped generation } \\
- & \text { RES generation } \\
- & \text { Cogeneration and rest }\end{array}$} & \multirow{10}{*}{$=$} & Liberalised suppliers & \multirow{10}{*}{ 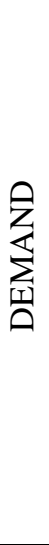 } \\
\hline & & & Last resort suppliers & \\
\hline & & & Auxiliary services consumption & \\
\hline & & & Direct consumers & \\
\hline & & & Balearic demand (HVDC Link) & \\
\hline & & & Pumped storage & \\
\hline & & & Standard losses & \\
\hline & & & Exports & \\
\hline & & & Real demand adjustments & \\
\hline & Imports & & & \\
\hline
\end{tabular}

Figure 4 shows the relationship between RDAs in relative terms and the ASCs in the Spanish 
market as a price spread. The graphs on the left show this relationship before the policy change while the graphs on the right show the relationship after the policy change.

Figure 4: Adjustment service costs versus real demand adjustments. This figure shows the relationship between the price spread explained by adjustment service costs ( $€ / M W h)(y-a x i s)$ and real demand adjustments ${ }^{6}$ (x-axis) before (B) (left hand side) and after (A) (right hand side) the policy change.
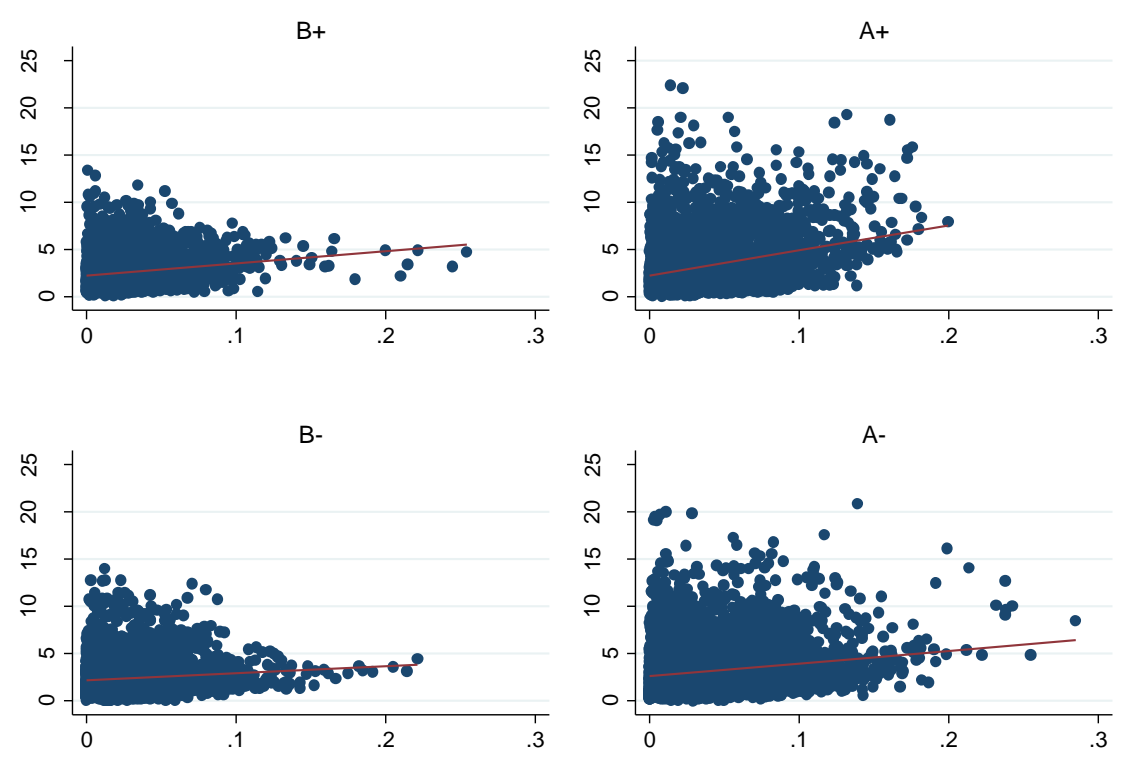

Given that for the Spanish electricity market, according to the imbalance price policy, a twoprice system scheme is used depending on the overall system situation, the analysis of the relation between the two variables needs to take this into consideration. Therefore, for the graphical representation we split the sample in two, depending on whether the system is characterised by over-deviations (long system position) and requires downward regulation energy (-) or by under-deviations (short system position) and requires upward regulation energy $(+)$.

As a different imbalance price is applied to positive and negative imbalance volumes, the analysis of the relationship between RDA in relative terms and adjustment services takes into consideration this fact, resulting in four possible scenarios: the relationship prior to policy change for hours requiring upward regulation energy $(\mathrm{B}+)$ or downward regulation energy $(\mathrm{B}-$ ) and after the policy change for hours requiring upward regulation energy $(\mathrm{A}+)$ or downward regulation energy (A-).

It seems quite apparent that the policy change has affected the relationship between RDAs and ASCs. First, both the graphs (Figure 4) and statistics (Table 2) suggest an increase in dispersion in terms of adjustment services with the highest costs being recorded following liberalisation.

\footnotetext{
${ }^{6}$ For simplicity of exposition we refer to the real demand adjustment in relative terms (\% over hourly final electricity demand) as real demand adjustment.
} 
As for RDAs, the graphs suggest a similar increase. At the same time, graphic analyses seem to indicate a change in the nature of the relationship between the two variables.

Table 2: Statistical representation of Figure 4

\begin{tabular}{|c|c|c|c|c|c|c|c|}
\hline & & & Obs. & Mean & Std. Dev. & Min & Max \\
\hline \multirow{4}{*}{$\begin{array}{l}\text { Real Demand } \\
\text { Adjustments }\end{array}$} & \multirow{2}{*}{ Before } & Negative & 5219 & 0.02908 & 0.02484 & 0 & 0.22114 \\
\hline & & Positive & 3540 & 0.02632 & 0.02422 & $8.81 \mathrm{E}-06$ & 0.25394 \\
\hline & \multirow{2}{*}{ After } & Negative & 5193 & 0.04491 & 0.0348 & 0 & 0.28484 \\
\hline & & Positive & 3566 & 0.03963 & 0.0319 & $3.13 \mathrm{E}-06$ & 0.19958 \\
\hline \multirow{4}{*}{$\begin{array}{l}\text { Adjustment } \\
\text { Service Costs }\end{array}$} & \multirow{2}{*}{ Before } & Negative & 5219 & 2.35953 & 1.62451 & 0 & 13.91 \\
\hline & & Positive & 3540 & 2.54883 & 1.67132 & 0 & 13.34 \\
\hline & \multirow{2}{*}{ After } & Negative & 5193 & 3.18603 & 2.5450 & 0 & 20.79 \\
\hline & & Positive & 3566 & 3.25166 & 2.93304 & 0 & 22.37 \\
\hline
\end{tabular}

After the policy change, in contrast with the situation prior to liberalisation, the graphic representation suggests that the relationship is no longer linear and is better fitted by a quadratic function. Indeed the scatter plots in Figure 5 seem to reveal a slight curvilinear shape to the data suggesting that a second-degree polynomial might be appropriate for modelling the data after the policy change. Therefore, both the linear and quadratic specifications are tested econometrically by performing two separate regressions (before and after the policy change). By including a dummy variable for liberalization interacted with the real demand adjustment (RDA) variable we could be able to capture the effect from the variable of interest. Nevertheless, when using the interacted dummy an underlying assumption is that the relation between the adjustment service cost (ASC) and the RDA it is linear during all the period. Given that for the period after the regulatory change the relation it is better fitted by a quadratic function, it seems more appropriate to split the sample instead of using the interacted dummy over the entire period.

Figure 5: Adjustment service costs versus real demand adjustments (quadratic relationship) 

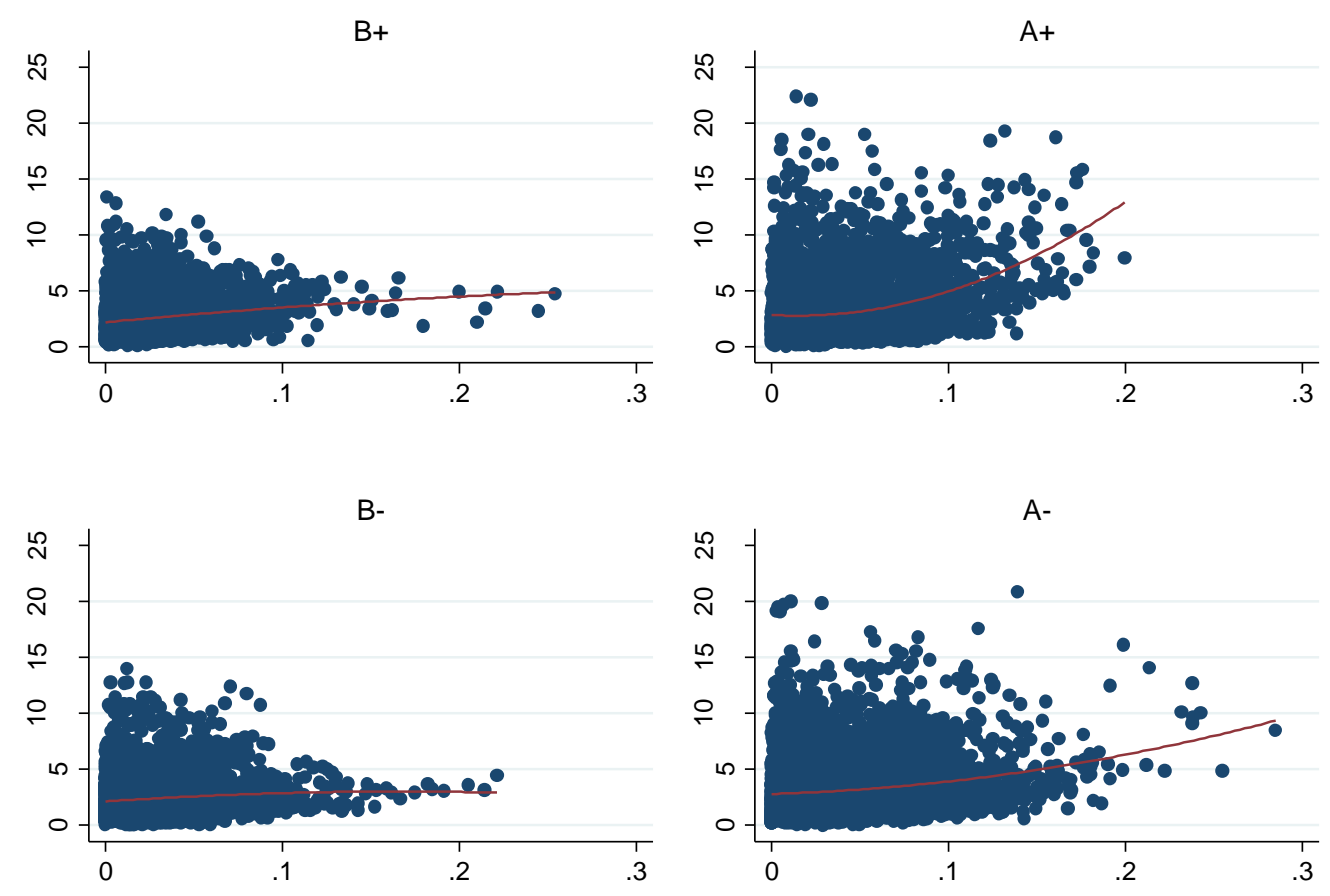

To conduct the econometric test, we use hourly market data for Spain for the period between 1 July 2008 and 30 June 2010, and construct a time series regression model controlling for seasonality. As the dependent variable, the econometric estimation uses the average weighted cost of the adjustment services. This variable, obtained as a price spread, includes the economic cost associated with all adjustment services - technical constraints, secondary control, tertiary control, power reserve, deviation management and real-time constraints. Hourly RDAs are used as the main explanatory variable.

Additionally, and in line with other electricity market price studies, we introduce an autoregressive component to capture dynamic effects on the adjustment costs. We introduce two additional control variables in our models. First, to control for consumption patterns on working and non-working days, we introduce a working day variable (WD). As electricity demand varies across the week, this temporary variable is introduced in the specification of the model in order to address aspects related to seasonality. Given notable differences between working days and the weekend, the model specification incorporates a dummy variable $(=1$ if a working day). Second, as the price of balancing power differs being on average positive balancing more expensive than negative balancing (Table 2), we introduce a second control variable $(U p R)$ for upward and downward energy regulation $(=1$ if the electricity system requires upward regulation). In Table 3 , we present the descriptive statistics of the variables employed.

Table 3: Summary statistics

\begin{tabular}{lccccc}
\hline Variable & Obs. & Mean & Std. Dev. & Min & Max \\
\hline $\boldsymbol{A} \boldsymbol{S C}$ & 17518 & 2.82441 & 2.27529 & 0 & 22.37 \\
\hline
\end{tabular}




\begin{tabular}{lllllc}
\hline $\boldsymbol{R D A}$ & 17518 & 0.03536 & 0.03048 & 0 & 0.28484 \\
\hline $\boldsymbol{W D}$ & 17518 & 0.69726 & 0.45946 & 0 & 1 \\
\hline $\boldsymbol{U p \boldsymbol { R }}$ & 17518 & 0.40570 & 0.49104 & 0 & 1 \\
\hline
\end{tabular}

Before presenting the time series regression models constructed for the analysis of the impact of the real demand adjustment on the adjustment cost, a stationary time series analysis was performed. We performed two tests: first, the augmented Dickey-Fuller (ADF) test (Dickey and Fuller, 1979) under the null hypothesis of a unit root; and, second, the KwiatkowskiPhillips-Schmidt-Shin (KPSS) tests (Kwiatkowski et al., 1992) under the null hypothesis of stationarity. Both tests ${ }^{7}$ confirm that the series are stationary in levels. In addition to the time series properties of the variables, an outlier analysis was performed rejecting the existence of extreme values ${ }^{8}$.

The model specification is defined in the following equations:

$$
\begin{gathered}
A S C_{t}=\alpha_{0}+\alpha_{1} A S C_{t-1}+\alpha_{2} R D A_{t}+\alpha_{3} W D_{t}+\alpha_{4} U p R_{t}+\varepsilon_{t} \\
A S C_{t}=\alpha_{0}+\alpha_{1} A S C_{t-1}+\alpha_{2} R D A_{t}+\alpha_{3} R D A_{t}^{2}+\alpha_{4} W D_{t}+\alpha_{5} U p R_{t}+\varepsilon_{t}
\end{gathered}
$$

The main difference between Eq. (6) and (7) is the inclusion of a quadratic component in the econometric model to test for a linear or polynomial relationship between the variables. In the least squares estimation of this dynamic model, it is evident that the unobserved initial values of the dynamic process induce a bias. Instrumental variable methods are able to produce consistent estimators for dynamic data models that are independent of the initial conditions. These estimators are based on the idea that lagged (or lagged differences of) regressors are correlated with the regressor included but are uncorrelated with the innovations. Thus, valid instruments are available from within the model and these can be used to estimate the parameters of interest employing instrumental variable methods. In this paper, the construction of instruments is done using values of the dependent variable lagged two periods and the lag of the exogenous variables, which are all independent of $\varepsilon_{t}$, to perform estimations using the instrumental variable regression method.

\section{RESULTS AND DISCUSSION}

To test the hypothesis of a differentiated impact of real demand adjustments on the costs of the system adjustment services resulting from the liberalisation we performed four sets of estimations corresponding to the two equations and time periods explained above. The estimation results are presented in Table 4, where the first two columns correspond to the linear

\footnotetext{
${ }^{7}$ The results for the ADF and KPSS tests are available upon request.

${ }^{8}$ As an additional time series test, we used the blocked adaptive computationally efficient outlier nominators (BACON) algorithm, as proposed by Billor et al. (2000) and further developed by Weber (2010), to detect outliers in our multivariate data. The results for the BACON test - available upon request - reject the existence of extreme values of the observable variables.
} 
model estimates (Eq. (6)) before and after the policy change. The first period covers the 12month period before the policy change (from 1 July 2008 to 30 June 2009) and the second period covers the 12-month period after the policy became effective (from 1 July 2009 to 30 June 2010). Analogously, the results in columns (3) and (4) correspond to the quadratic model estimates (Eq. (7)) before and after the policy change.

Table 4: Impacts on the system adjustment service costs before and after liberalisation

\begin{tabular}{|c|c|c|c|c|}
\hline & \multicolumn{2}{|c|}{ Linear } & \multicolumn{2}{|c|}{ Quadratic } \\
\hline & $\begin{array}{l}\text { (Before) } \\
\text { (1) }\end{array}$ & $\begin{array}{l}\text { (After) } \\
(2)\end{array}$ & $\begin{array}{c}\text { (Before) } \\
\text { (3) }\end{array}$ & $\begin{array}{c}\text { (After) } \\
\text { (4) }\end{array}$ \\
\hline$R D A$ & $\begin{array}{c}2.766^{* * * *} \\
(0.339)\end{array}$ & $\begin{array}{c}6.200 * * * \\
(0.445)\end{array}$ & $\begin{array}{c}2.259 * * * \\
(0.694)\end{array}$ & $\begin{array}{l}1.875^{*} \\
(1.090)\end{array}$ \\
\hline$R D A^{2}$ & & & $\begin{array}{c}4.901 \\
(5.851)\end{array}$ & $\begin{array}{c}34.04 * * * \\
(7.814)\end{array}$ \\
\hline$W D$ & $\begin{array}{c}0.0603 * * * \\
(0.0181)\end{array}$ & $\begin{array}{c}0.0792 * * \\
(0.0321)\end{array}$ & $\begin{array}{c}0.0609 * * * \\
(0.0181)\end{array}$ & $\begin{array}{r}0.0848 * * * \\
(0.0321)\end{array}$ \\
\hline$U p R$ & $\begin{array}{c}0.0848 * * * \\
(0.0167)\end{array}$ & $\begin{array}{l}0.155^{* * * *} \\
(0.0298)\end{array}$ & $\begin{array}{c}0.0843 * * * \\
(0.0167)\end{array}$ & $\begin{array}{c}0.153^{* * * *} \\
(0.0298)\end{array}$ \\
\hline L.ar & $\begin{array}{l}0.871 * * * \\
(0.00569)\end{array}$ & $\begin{array}{l}0.851 * * * \\
(0.00639)\end{array}$ & $\begin{array}{l}0.871 * * * \\
(0.00570)\end{array}$ & $\begin{array}{l}0.848 * * * \\
(0.00640)\end{array}$ \\
\hline Constant & $\begin{array}{c}0.161 * * * \\
(0.0224)\end{array}$ & $\begin{array}{c}0.0962 * * \\
(0.0389)\end{array}$ & $\begin{array}{c}0.167 * * * \\
(0.0239)\end{array}$ & $\begin{array}{c}0.186^{* * * *} \\
(0.0438)\end{array}$ \\
\hline Observations & 8,759 & 8,759 & 8,759 & 8,759 \\
\hline $\begin{array}{l}R \text {-squared } \\
d y d x\left(R D A \& R D A^{2}\right)\end{array}$ & 0.786 & 0.746 & $\begin{array}{c}0.783 \\
2.5767\end{array}$ & $\begin{array}{c}0.741 \\
4.0833 * * *\end{array}$ \\
\hline
\end{tabular}

Overall, the results show that, as a consequence of liberalisation, the system's ASCs increased. In general, the constant is higher after the policy change than before; hence, regardless of the impact of the RDAs, the weekly seasonality and the type of energy regulation, the ASCs increased after liberalisation. These results are indicative of the general impact but they are not specifically what we are interested in, as our objective is to determine if the ASCs fluctuate as a consequence of the change in the relation between the costs and the real demand adjustments attributable to the new role played by the DSO following liberalisation.

Based on the graphical representation presented in section 3 above, we hypothesised that the nature of the relationship between RDAs and ASCs differed before and after the implementation of the policy, and we estimated linear and quadratic functions to test this. The results confirm that, while before liberalisation the relationship between the two variables had a linear form (the coefficient of $R D A^{2}$ in column (3) is not significant), after the policy change it takes a quadratic form (the coefficient of $R D A^{2}$ in column (4) is significant). These results are of particular relevance since they imply that following liberalisation the impact of demand adjustments on the ASCs have become increasingly stronger. 
The short-run marginal effects of these regression results provide additional insights into the magnitude of the implications of the policy change (see Table 5). Before liberalisation each MWh of RDA generated an adjustment services cost of $2.76 € / \mathrm{MWh}$; after liberalisation the same demand adjustment generates an ASC of $4.08 € / \mathrm{MWh}$. This means that the immediate direct effect of the policy change is an increase of $47.8 \%$ (see first line of Table 6). However, to place these figures in the right perspective, we need to take into account that the ASCs differ in both periods; hence, we divided the previous effects by the average value of the ASCs. The results indicate that on average each MWh of RDA generated a $12.7 \%$ increase in ASCs before and $26.90 \%$ after liberalisation (see second line of Table 5).

Table 5: Short-Run Marginal Effects

\begin{tabular}{cccc}
\hline & Before & After & Diff (B vs. A) \\
\hline $\mathbf{d y} / \mathbf{d x}$ & 2.76 & 4.08 & $47.80 \%$ \\
$(€ / \mathrm{MWh})$ & & & \\
\hline$(\mathbf{d y} / \mathbf{d x}) / \overline{\mathbf{y}}$ & $12.70 \%$ & $26.90 \%$ & $14.20 \%$ \\
\hline
\end{tabular}

The difference in the marginal effects from each MWh of RDA on the average ASCs can be used to measure the monetary cost of the policy. By multiplying this difference in the marginal effects $(14.20 \%)$ and the average ASCs after the regulatory change, we find that the additional cost is $0.348 €$ per MWh consumed. With this information, and taking into account that total consumption in the 12-month period following the policy change (July 2009 to June 2010) was $257 \mathrm{TWh}$, the impact of liberalisation on the adjustment services represented an overall cost of 90 million $€ /$ year.

As for the dynamic component, our results indicate that the ASCs depend heavily on their value in the previous hour. Hence, depending on the model and period considered, a $1 € / \mathrm{MWh}$ increase in the level of ASCs in the previous hour increases the costs by between 0.84 and 0.87 $€ / M W h$. The inertial behaviour of the system adjustment costs, related to the criteria followed by the SO to assess control reserves, seems to account for these outcomes.

Finally, our results for the additional control variables are in line with expectations. First, we find that the effect of the positive energy market balance on the adjustment costs is always higher than that of the negative balance. These results are as expected for this control variable, since it captures the fact that adjustment services are more costly when the system requires upward regulation than when it requires downward regulation. The costs of balancing power are heavily dependent on the kind of generation technology used for regulation (Holttinen, 2005, Holttinen et al., 2011), with hydropower being the cheapest option and gas turbines the most expensive, as well as the overall situation of the system. From a cost perspective, it is not the same to be in a long system position requiring downward regulation energy, as it is to be in a short system position requiring upward regulation energy. The explanation for this price 
differential lies in the fact that to provide upward regulation, the generation resources must set some generation capacity aside, which could otherwise have been traded in the power markets. The provision of downward regulation merely requires that the generation unit be able to ramp down (Van der Veen et al., 2010). And second, the variable capturing the seasonality of electricity demand across the week is positive and significant in all regressions. This positive effect seems to be related to the amount of generation connected to the system that is capable of providing flexible services to the system. Over the weekend, a similar pattern of VRES generation to that recorded on a working day may result in a low net demand. Under such a scenario, conventional generation could increase its participation in the adjustment services markets in order to complete the generation program and in this way avoid shutting down only to have to start up a few hours later.

\section{CONCLUSIONS AND POLICY IMPLICATIONS}

Electricity markets across Europe had undergone an institutional transition. To enhance economic efficiency and improve services to the consumer, European electricity markets had been liberalised, leading to the introduction of competition and opening of the markets. In this process, the current role of some agents, such as DSOs has changed being its role strongly influenced by the unbundling measures introduced in the regulatory framework. In this regard, the Second Electricity Directive implied a change in the duties and responsibilities of Spanish DSOs.

When discussing the best way to achieve competitive and integrated European electricity retail markets, this change has to be considered in general terms as positive and DSOs should be seen as key agents in the liberalisation process (Eurelectric, 2010). For this reason, this paper has not sought to question the decisions taken within the framework of the EU's directives. Indeed, DSOs have been shown to be instrumental in the roll-out of smart grids and smart meters, and to have played a leading role in aggregation, demand response and energy efficiency, among other relevant aspects. The drawback analysed in this paper is not that distribution companies are not suppliers of energy in the retail market, but rather that the regulatory framework should have anticipated the economic impact associated with the change of scheme by establishing corrective measures.

Under the new liberalised scenario, energy suppliers have to estimate demand in order to make sure that sufficient supply is available on different timescales. Calculating both the total electricity demand and the specific electricity demand for different uses based on limited metered data constitutes a common problem across Europe, not being Spain an exception. Under a similar methodological approach to estimate the electricity demand, differences arise when considering the technical aspects involved in the construction of the different load profiles and losses coefficients trying all these methods to provide the most representative patterns for electricity usages for the different segments of liberalised customers.

In terms of policy implications, when analysing this kind of policy changes, under our opinion, the most relevant question to be addressed is the relevance of the regulatory framework and its 
ability to anticipate the effects that stem from these changes being able to provide satisfactory answers. The success of this kind of transformation process is what underpins a smart regulation; that is, one that is capable of providing solutions to unexpected outcomes during the process. Our paper has sought to contribute to existing knowledge regarding the economic effects of liberalisation in the power system by examining a natural experiment associated with the regulatory changes introduced in Spain in 2009. Since then, regulated supply by DSOs has disappeared. This positive change in terms of retail market competition, as we have shown in this paper, had unexpected collateral effects in terms of the system's balancing requirements.

In this sense, the policy change introduced in July 2009 regarding the role of the DSOs is relevant for the evolution in adjustment costs in Spain. From this date, the suppliers are the only ones responsible to estimate demand in order to make sure that sufficient supply is available on different timescales. Hourly consumption for all customers on a daily basis is estimated based on load profiles and loss coefficients determined ex-ante. To the extent that electricity balance, resulting from the difference between the measured losses in transmission and distribution and the standard losses used in the balancing procedure of the system as a whole, requires additional adjustment services, the policy directly increased the energy requirements associated with the electricity market balance. In this sense, this paper provides an economic estimation of the economic impacts of this policy on adjustment services costs and, hence, on final electricity prices.

Although in 2009 the combined day-ahead and intraday market prices accounted for $89 \%$ of the final price, whilst the cost resulting from the management of system adjustment services accounted for just $6.3 \%$, the impact of these latter costs on the final price of energy has grown substantially. In the first year of policy change, the amount of energy managed in the system adjustment services markets was $23,918 \mathrm{GWh}, 34.9 \%$ higher than in the previous year, a clear indication that something was amiss in the adjustment services markets. Isolating the economic effects attributable to the policy change, we find that the extra cost in relative terms was around $0.348 €$ per MWh consumed. Thus, in the first year alone, the effects of liberalisation via the real demand adjustment on the adjustment services represented an overall cost of 90 million $€$.

This increase in terms of the costs linked to adjustment services is relevant both from a macro and microeconomic point of view. At a time when energy prices are raising concerns about the impact on economic competitiveness, it becomes increasingly relevant from a macroeconomic perspective to identify any source of distortion affecting final electricity prices. At the same time, from a microeconomic perspective it should be stressed that any unexpected increase in the adjustment service costs has a marked impact on the results of independent electricity retailers. While the price risk associated with unexpected variations in the day-ahead market price could be covered on the futures markets, unforeseen variations in the cost of adjustment services could not be covered. Therefore, an unexpected increase in adjustment service costs has a direct impact on the business results of retailers - especially on those of new entrants. This highlights the importance of the analysis undertaken in this paper. An in-depth understanding of the factors that account for the evolution of operational costs will ultimately be helpful when making improvements to the regulatory framework to facilitate the success of retail market competition, specially in a context where the flexibility requirements have 
increased over the last few years. Although this study is applied to Spain the results are of general interest to other countries mainly because the more common regulatory design within the EU on liberalisation promotion is applied. The Spanish experience provides useful insight to other countries where the process of liberalisation of the retail market is at early stages.

From a short- and medium-term perspective, improvements have to be introduced. Smart metering is a highly promising technology, which will greatly empower electricity customers to become active managers of their consumption. At the same time, smart meters should result in the optimisation of the overall electricity distribution infrastructure. The expected large-scale deployment of smart meters in Spain will enable both suppliers and DSOs to use more accurate individual consumption data (load profiles) in their processes. Nevertheless, in the short-term, measures such as those introduced in June 2014, aimed at establishing standard coefficients of losses and load profiles that take into account different time and seasonal patterns should facilitate a reduction in associated costs. Since the initiation of liberalisation, costs of at least 450 million $€$ have been borne by final consumers. The transformation would probably have been faster if instead of socialising through the final price of electricity, the extra cost had been assigned to a specific agent (e.g., the last resort or liberalised supplier). During this five-year period, no price signal was given to the suppliers - or to the regulator who had ultimate responsibility for determining the standard coefficients of losses - because of the greater requirements of flexibility expected in the system.

Behind every major change, such as the transformation ushered in by the liberalisation of the electricity market, it is critical that the details of the process be carefully examined. The challenges faced in attaining the goals set are largely determined by regulatory issues or, more specifically, by micro-regulations and their implementation. It is, obviously, vital to assess the economic consequences for the whole system of any policy change, especially if the intention of a smart regulation is to benefit all consumers. In the context of growing concern about competiveness, the wise use of available resources and the employment of smart market policy tools are essential if we are to benefit fully from sustainable and reliable power systems.

Although this study is applied to Spain the results are of general interest to other countries mainly because the most common regulatory design within the EU on liberalisation promotion is applied. The Spanish experience provides useful insight to other countries where the process of liberalisation of the retail market is at early stages.

\section{ACKNOWLEDGEMENTS}

We would like to thank the two anonymous referees for helpful comments and suggestions. We are also grateful for the support of the Generalitat de Catalunya SGR project 2014-SGR531 and from the Chair on Energy and Environmental Sustainability (University of Barcelona and FUNSEAM).

\section{REFERENCES}


Billor, N., Hadi, A.S., Velleman, P.F., 2000. BACON: Blocked adaptive computationally efficient outlier nominators. Computational Statistics \& Data Analysis 34, 279-298.

Bueno-Lorenzo, M., Moreno, M.Á., Usaola, J., 2013. Analysis of the imbalance price scheme in the Spanish electricity market: A wind power test case. Energy Policy 62, 1010-1019.

Cancelo, J.R., Espasa, A., Grafe, R., 2008. Forecasting the electricity load from one day to one week ahead for the Spanish system operator. Int. J. Forecast. 24, 588-602.

Dickey, D. A., Fuller, W.A., 1979. Distribution of the Estimators for Autoregressive Time Series with a Unit Root. Journal of the American Statistical Association 74, 427-431.

Ela, E., Milligan, M., Bloom, A., Botterud, A., Townsend, A., Levin, T., 2014. Evolution of Wholesale Electricity Market Design with Increasing Levels of Renewable Generation.

Eurelectric, 2010. Integrating intermittent renewables sources into the EU electricity system by 2020: challenges and solutions. Union of the Electricity Industry (EURELECTRIC). Brussels.

Federico, G., 2010. The Spanish Gas and Electricity Sector : Regulation, Markets and Environmental Policies. Madrid.

Frunt, J., 2011. Analysis of balancing requirements in future sustainable and reliable power systems. Eindhoven, Technische Universiteit.

Glachant, J.-M., Finon, D., 2010. Large-scale wind power in electricity markets. Energy Policy 38, 6384-6386.

Haas, R., Lettner, G., Auer, H., Duic, N., 2013. The looming revolution: How photovoltaics will change electricity markets in Europe fundamentally. Energy 57, 38-43.

Hirth, L., Ueckerdt, F., Edenhofer, O., 2015. Integration Costs Revisited - An Economic Framework for Wind and Solar Variability. Renew. Energy 74, 925-939.

Hirth, L., Ziegenhagen, I., 2015. Balancing Power and Variable Renewables: Three Links. Renew. Sustain. Energy Rev. 50, 1035-1051.

Holttinen, H., 2005. Optimal electricity market for wind power. Energy Policy 33(16), 2052-2063.

Holttinen, H., Meibom, P., Orths, A., Lange, B., O’Malley, M., Olav, J., Estanqueiro, A., Gomez, E., Söder, L., G. Strbac, Smith, J.C., van Hulle, F., 2011. Impacts of large amounts of wind power on design and operation of power systems, results of IEA collaboration. Wind Energy 14 (2), 179-192.

Hummon, M., Denholm, P., Jorgenson, J., Palchak, D., Kirby, B., Ma, O., 2013. Fundamental Drivers of the Cost and Price of Operating Reserves Fundamental Drivers of the Cost and Price of Operating Reserves. NREL Technical Report (NREL/TP-6A20-58491).

International Energy Agency, 2009. Design and Operation of Power Systems with Large Amounts of Wind Power. IEA Wind Task 25. Helsinki

International Energy Agency, 2011a. Deploying Renewables 2011: Best and Future Policy Practice. OECD/IEA. Paris.

International Energy Agency, 2011b. Harnessing Variable Renewables. OECD/IEA. Paris.

Kwiatkowski, D., Phillips, P.C.B., Schmidt, P., Shin, Y., 1992. Testing the Null Hypothesis of Stationarity against the Alternative of a Unit Root. Journal of Econometrics 54, 159-178.

Lobato, E., Egido, I., Rouco, L., López, G., 2008. An Overview of Ancillary Services in Spain. Electric Power Systems Research 78(3), 515-23. 
Perez-Arriaga, I. J., Batlle, C., 2012. Impacts of Intermittent Renewables on Electricity Generation System Operation. Economics of Energy \& Environmental Policy 1(2), 3-18.

Ramanathan, R., Engle, R., Granger, C.W.J., Vahid-Araghi, F., Brace, C., 1997. Shorte-run forecasts of electricity loads and peaks. Int. J. Forecast. 13, 161-174.

Soares, L.J., Medeiros, M.C., 2008. Modeling and forecasting short-term electricity load: A comparison of methods with an application to Brazilian data. Int. J. Forecast. 24, 630-644.

Taylor, J.W., de Menezes, L.M., McSharry, P.E., 2006. A comparison of univariate methods for forecasting electricity demand up to a day ahead. Int. J. Forecast. 22, 1-16.

Vandezande, L., Meeus, L., Belmans, R., Saguan, M., Glachant, J.M., 2010. Well-functioning balancing markets: A prerequisite for wind power integration. Energy Policy 38 (7), 3146 - 3154.

Weber, S., 2010. BACON: An Effective Way to Detect Outliers in Multivariate Data Using Stata (and Mata). Stata Journal 10(3), 331-338. 


\section{Appendix: Technical aspects underpinning the energy market balance}

In a liberalised framework, suppliers buy the total amount of energy required to fulfil the expected demand of their customers on the electricity markets. Suppliers determine hourly electricity demand using different forecast methods and techniques. In order to avoid the extracosts associated with higher prices on the different markets after day-ahead market gate closure, the supplier seeks to achieve the best possible demand estimation. In this way, suppliers aim at covering their demand on the day-ahead market without their having to make adjustments on posterior markets, which typically are more expensive.

As the majority of customers are connected at low voltage (LV) level $(<1 \mathrm{kV})$, the suppliers' demand has to take into account total network electricity losses. For each hour and for each voltage level, suppliers have to include total estimated losses ${ }^{9}$ in their bids for the day-ahead market. According to the methodology established by Spain's electricity legislation, energy losses are allocated to each consumer taking into consideration their consumption characteristics. More specifically, the allocation of losses is the result of multiplying the enduse meter data of each consumer by a standard loss coefficient (transmission and distribution loss factor). Therefore, the expected hourly electricity demand of each supplier, measured at the power station busbars, is:

$$
E_{j}^{h}=\sum_{i=1}^{n}\left(E_{i}^{h} \cdot\left(1+K_{i}^{h}\right)\right)
$$

being:

$E_{j}^{h}: \quad$ Expected hourly electricity demand of each supplier $(j)$, with $h=1, \ldots, 24$.

$E_{i}^{h}: \quad$ Expected hourly electricity demand of each category of consumer differentiated by voltage level $(i)^{10}$.

$K_{i}^{h}$ : Hourly standard losses coefficient differentiated by voltage level $(i)$, with $i=$ $1, \ldots, n$.

Standard loss coefficients $\left(K_{i}^{h}\right)$ are used to calculate the standard network losses of the distribution companies, which are charged to consumers through full-service and access tariffs.

According to Eq. (A1), the energy metered at each connection point between the transmission and distribution grids has to be increased by the corresponding percentage of losses. For those consumers - mainly domestic and residential - that are not metered on a time interval basis, electricity demand is calculated using load profiles. In general, adopting different approaches,

\footnotetext{
${ }^{9}$ Total losses are determined as the difference between the energy metered at transmission and distribution network entry points and the energy metered at distribution network exit points (energy billed to customers). Total losses can be divided (Sáenz et al., 2011) into two different groups depending on their nature: technical losses caused by current flowing though the network and non-technical losses mainly caused by theft, fraud or administrative errors among other explanatory factors.

${ }^{10}$ In Spain, coefficients are differentiated according to the voltage level (n) of the network to which the customer is connected: high voltage (HV) network $(36-220 \mathrm{kV})$, medium voltage $(\mathrm{MV})$ network $(1-36 \mathrm{kV})$ and low voltage $(\mathrm{LV})$ network $(<1 \mathrm{kV})$. In this regards, the expected hourly demand $\left(E_{i}^{h}\right)$ results from the load aggregation corresponding to customers connected to the $\mathrm{n}$ different voltage levels.
} 
load profiles seek to characterize domestic electricity patterns of use on an intra-daily, diurnal and seasonal basis as a function of consumer characteristics. In the case of Spain, static profiles are derived from consumption data for each time interval considered, as collected from existing historic demand records for a sufficiently large sample of customers. With this information, which takes into account factors that might affect consumption and which might vary from day to day as well as from year to year (variations in the weather, holiday periods, etc.), domestic standard load profiles are constructed aimed at determining aggregate electricity consumption for all households without hourly metering across a 24- hour period. Profiling enables an electricity supplier to calculate the electricity consumption for every pricing period on the market (hourly time intervals in the case of Spain) for its customers that do not have a time interval meter installed.

Load profile-based metering implies that the expected hourly electricity demand of each category of consumer $\left(E_{i}^{h}\right)$ is calculated as:

$$
E_{i}^{h}=\sum_{i=1}^{n}\left(E_{i}^{d} \cdot L_{i}^{h}\right)
$$

being:

$E_{i}^{d}: \quad$ Expected daily electricity demand.

$L_{i}^{h}: \quad$ Average load profile of a class of customers (i) over a given hour $(h)$.

In short, the expected hourly electricity demand $\left(E_{j}^{h}\right)$, based upon estimates using standard loss coefficients $\left(K_{i}^{h}\right)$ and load profiles $\left(L_{i}^{h}\right)$, constitutes the basis for the supplier to purchase from the wholesale market the electricity required by its customers. However, the use of both adjustment parameters has certain implications for the energy finally contracted. As the annual losses have been determined ex ante using standard loss coefficients, their value will not coincide with the real value of annual technical losses in the network. Likewise, the use of load profiling to determine a consumer's electricity consumption inherently introduces discrepancies between estimated and real load $\left(E_{r}^{h}\right)$, therefore:

$$
E_{s}^{h} \neq E_{r}^{h}
$$

being:

$E_{S}^{h}: \quad$ Expected total hourly electricity demand obtained as the sum of the expected hourly electricity demand of each supplier $(j)$ :

$$
E_{s}^{h}=\sum_{j=1}^{J} E_{j}^{h}
$$

$E_{r}^{h}: \quad$ Real hourly electricity demand

As discussed above, given that the energy finally dispatched to meet the customers' energy requirements, is not necessarily the same as that initially expected by the suppliers, a positive 
or negative energy difference arises, for which a balancing process is required. The electricity market balance requires additional adjustment services to ensure that generation and demand are in permanent equilibrium. This duty lies primarily with the system operator (SO). As the entity with overall responsibility for short-term system operation, the SO normally handles the balance-settlement and generation-load reconciliation process via processes of adjustment services management.

The post-liberalisation model of energy imbalance described above differs from the preliberalisation model. Under the pre-liberalisation system, the energy imbalance was resolved by the DSOs permanently matching electricity demand forecasts with the energy actually dispatched. Here, the electricity supply $\left(E_{S}^{h}\right)$ was provided at a regulated tariff $\left(E_{\text {reg }}^{h}\right)$ through a distribution company or at a market price $\left(E_{l i b}^{h}\right)$ through a supplier. The energy demanded in the wholesale market was equivalent to consumption measured at the power station busbars thanks to DSOs who adjusted their demand in the power exchange in an attempt at minimising the energy market balance.

In this pre-liberalisation scheme, where the liberalised and regulated supply coexisted, demand from distribution companies $\left(E_{r e g}^{h}\right)$ was determined at the border point in the distribution grid - affected by the corresponding loss profiles and standard coefficients - after subtracting the energy belonging to the liberalised customers $\left(E_{l i b}^{h}\right)$ connected to the distribution area. In the post-liberalisation model, with the disappearance of the distributor as a supplier of electricity, the previous scheme was no longer valid. The estimated hourly electricity demand is calculated as it was previously for the consumption of the liberalised customers but distributors make no adjustments. This means that the hourly energy demand on the market estimated by suppliers does not coincide with the electricity finally dispatched. The SO therefore uses ancillary services to correct this difference. The pre- and post-liberalisation loss adjustment schemes are summarised in Table A.1.

Table A.1: Main implications in terms of electricity losses

\begin{tabular}{lcc}
\hline & Before July 2009 & After July 2009 \\
\hline Estimated versus real load & $E_{s}^{h}=E_{r}^{h}$ & $E_{s}^{h} \neq E_{r}^{h}$ \\
\hline Losses adjustment process & $E_{r e g}^{h}=E_{s}^{h}-E_{l i b}^{h}$ & $E_{r}^{h}-E_{s}^{h}=E M B$ \\
& & $E M B$ is adjusted in the balancing \\
& & markets \\
\hline
\end{tabular}

Under a similar approach aimed at reducing system costs through the use of standard coefficient of losses that better capture time and seasonal patterns, across Europe the differences from system to system remain in the specificities. Technical aspects related with the methods for establishing the difference between estimated and actual consumption and the price at which this difference is settled constitute the main difference from system to system. According to Spanish legislation, the day-ahead price is used to clear the differences between the system's real losses and those resulting from the application of a standard coefficient of losses. 